\title{
HUBUNGAN KARAKTERISTIK INDIVIDU DAN DUKUNGAN KELUARGA DENGAN KUALITAS HIDUP PENDERITA KANKER SERVIKS
}

\author{
Mayang Wulan
}

Kebidanan, Institut Kesehatan Helvetia, Prodi D4 Kebidanan, email: Mayangwulan@helvetia.ac.id

INFO ARTIKEL
Riwayat Artikel:
Diterima: 12-06-2019
Disetujui: $11-07-2019$

Kata Kunci:

Karakteristik Individu Dukungan Keluarga

Kualitas Hidup

Kanker Serviks

\begin{abstract}
ABSTRAK
Abstrak: Data Kementerian Kesehatan Republik Indonesia, penyakit kanker serviks merupakan kanker dengan pravalensi penderita tertinggi di Indonesia pada tahun 2013 yaitu 0,8\% atau diperkirakan sebanyak 98.692 penderita. Penelitian ini menggunakan metode campuran yaitu metode kuantitatif dan kualitatif dengan strategi eksplanatoris sekuensial. Terdapat hubungan signifikan antara karakteristik individu (pengetahuan) dengan kualitas hidup penderita kanker serviks. Hasil studi kualitatif dan kuantitatif saling menguatkan dan pada hasil kualitatif mengenai faktor yang berhubungan kualitas hidup didapatkan faktor baru yaitu religiusitas. Kepada petugas kesehatan yang bertugas di RSUD. Dr. Pirngadi Kota Medan agar berupaya meningkatkan pengetahuan menambah pemahaman tentang kanker serviks sehingga kualitas hidup penderita mengarah ke arah yang lebih baik.
\end{abstract}

\begin{abstract}
Data from the Health Ministry of Republic of Indonesia, the cervical cancer is the cancer with the highest patient pravalention in Indonesia in 2013 is estimated at $0.8 \%$ or 98 692 people. This study used mixed methods, namely quantitative and qualitative methods with sequential explanatory strategy, this strategy was applied to the collection and analysis of quantitative data in the first phase followed by the collection and analysis of qualitative data in the second phase that builds on the initial results of the quantitative.There is significant influence between individual characteristics (knowledge) on the quality of life of patients with cervical cancer. The results of qualitative and quantitative studies reinforce each other and on the qualitative results regarding the factors that corelation the quality of life obtained a new factor, namely religiosity. It is suggested to health workers on duty in Dr. Pirngadi general hospital Medan to improve the knowledge understanding of cervical cancer so that the quality of life of patients leads to a better direction.
\end{abstract}

\section{A. LATAR BELAKANG}

Kanker serviks (Cervical Cancer) atau kanker pada leher rahim adalah kanker yang terjadi pada serviks uterus, suatu daerah pada organ reproduksi wanita yang merupakan pintu masuk ke arah rahim yang terletak antara rahim (uterus) dengan liang senggama (vagina). Kanker ini biasanya terjadi pada wanita yang telah berumur, tetapi bukti statistik menunjukkan bahwa kanker leher rahim dapat juga menyerang wanita yang berumur antara 20 sampai 30 tahun. (Kasdu 2005)

Kanker serviks adalah suatu proses keganasan yang terjadi pada serviks, sehingga jaringan di sekitarnya tidak dapat melaksanakan fungsi sebagaimana mestinya. Keadaan tersebut biasanya disertai dengan adanya perdarahan dan pengeluaran cairan vagina yang abnormal, penyakit ini dapat terjadi berulang-ulang (Darmawati 2010). Kanker serviks merupakan kanker yang paling sering keempat pada wanita dengan perkiraan 530.00o kasus baru pada tahun 2012 di seluruh dunia, yang mewakili 7,5\% dari semua kematian akibat kanker perempuan.
Sekitar 270.00o wanita meninggal karena kanker serviks pada tahun 2012, lebih dari 85\% dari kematian ini terjadi di negara-negara berpenghasilan rendah dan menengah.(Lestari, Yuli Kusumawati, and Werdani 2016).

Berdasarkan data Kementerian Kesehatan Republik Indonesia(Indonesia 2013), penyakit kanker serviks merupakan kanker dengan pravalensi penderita tertinggi di Indonesia pada tahun 2013 yaitu o,8\% atau diperkirakan sebanyak 98.692 penderita. Provinsi Kepulauan Riau, Provinsi Maluku Utara, Provinsi D.I Yogyakarta memiliki pravalensi kanker serviks tertinggi di Indonesia yaitu sebesar 1,5\%, Provinsi Sumatera Utara pada tahun 2013 menempati urutan kesembilan dengan pravalensi yaitu sebanyak $0,7 \%$ atau diperkirakan sebanyak 4.694 penderita.(Gustiana, Dewi, and Nurchayati 2014)

Gejala bagi beberapa orang pada tahap awal penyakit kanker serviks tidak menimbulkan gejala yang mudah diamati. Gejala fisik serangan penyakit kanker serviks pada umumnya hanya dirasakan oleh penderita kanker stadium lanjut, yaitu munculnya rasa 
sakit dan perdarahan saat berhubungan intim (contact bleeding), keputihan yang berlebihan dan tidak normal, perdarahan diluar siklus menstruasi, serta penurunan berat badan secara drastis.(Wigati 2016) Hal ini membuat penderita mengalami perubahanperubahan fisik dan psikologis yang menimbulkan berbagai keluhan baik fisik maupun psikologis dan akan memengaruhi kualitas hidupnya (Hasnani 2012).

Faktor risiko kanker serviks yaitu terjadi pada wanita perokok lebih besar kemungkinannya terkena kanker serviks dibandingkan wanita yang tidak merokok. (Imam Rasjidi 2013).Infeksi Human Immunodefeciency Virus (HIV), infeksi klamidia, diet rendah sayuran dan buah-buahan, pemakaian pil KB, wanita yang menjalani 3 atau lebih kehamilan, hamil pertama di usia muda, wanita-wanita miskin atau berpenghasilan rendah, pemakaian diethylstilbestrol (DES) dan riwayat (bila seorang wanita mempunyai ibu atau kakak perempuan yang menderita kanker serviks) juga termasuk ke dalam faktor risiko terjadinya kanker serviks.(Sulistiowati and Sirait 2015).

WHOQoL group pada tahun 2004 menyebutkan dimensi kualitas hidup terdiri dari 4 dimensi yaitu dimensi kesehatan fisik, kesehatan psikologis, hubungan sosial dan lingkungan. (Rohmah and Bariyah 2015).

Penelitian studi kualitatif tentang kualitas hidup pada penderita kanker serviks yang menjalani radioterapi oleh Fitriana(Fitriana and Ambarini 2012) Berdasarkan survei awal dari hasil wawancara yang dilakukan di RSUD Dr. Pirngadi Kota Medan kepada 2 penderita kanker serviks, masing-masing menderita Penderita kanker serviks yang menjalani pengobatan radioterapi mencapai kualitas hidup yang baik melalui upaya mendekatkan diri pada Tuhan seperti memperbanyak berdoa, selalu berpikir positif serta menjalani setiap prosedur dan proses pengobatan dengan baik sesuai anjuran dokter. Penelitian kuantitatif yang dilakukan oleh Zega(Zega and Siregar 2013) tentang kualitas hidup pasien kanker payudara yang menjalani kemoterapi di Rumah Sakit Umum Pusat Haji Medan pada tahun 2013 dari 33 orang yang sesuai dengan kriteria pasien kanker payudara yang telah menjalani kemoterapi minimal 2 kali yang mempunyai kualitas hidup baik 14 orang $(42,4 \%)$ dan kualitas hidup cukup 19 orang (57,6\%).

Dukungan keluarga erat kaitannya dalam menunjang kualitas hidup seseorang. Hal ini dikarenakan kualitas hidup merupakan suatu persepsi yang hadir dalam kemampuan, keterbatasan, gejala serta sifat psikososial hidup individu baik dalam konteks lingkungan budaya dan nilainya dalam menjalankan peran dan fungsi sebagaimana mestinya. (Creswell 2010)

\section{B. METODE PENELITIAN}

Penelitian ini menggunakan metode campuran yaitu metode kuantitatif dan kualitatif dengan strategi eksplanatoris sekuensial. Proses pencampuran (mixing) data dalam strategi ini terjadi ketika hasil awal kuantitatif menginformasikan proses pengumpulan data kualitatif. Untuk itulah, dua jenis data ini terpisah, namun tetap berhubungan.(Creswell 2010) Jenis penelitian kuantitatif dalam penelitian ini dengan menggunakan pendekatan cross sectional (potong silang).

Jenis penelitian kualitatif dalam penelitian ini dengan menggunakan dengan jenis penelitian naratif. Penelitian ini dilakukan di ruang rawat inap dan dan ruang rawat jalan di RSUD Dr. Pirngadi Kota Medan. Populasi dalam penelitian ini adalah pasien kanker serviks di RSUD Dr. Pirngadi Kota Medan sebanyak 31 orang. Pada penelitian didapatkan dari 31 populasi 2 orang sudah pindah rumah sakit dan 2 orang lagi sudah meninggal dunia sehingga populasi menjadi berjumlah 27 orang. Sampel dalam penelitian ini adalah seluruh pasien kanker serviks pada bulan Januari-Juni di RSUD Dr. Pirngadi Kota Medan sebanyak 27 orang.

\section{HASIL DAN PEMBAHASAN \\ 1. Hasil Kuantitatif}

TABEL 1

Tabulasi Silang Hubungan Usia dengan Kualitas Hidup Penderita Kanker Serviks

\begin{tabular}{|c|c|c|c|c|c|c|c|c|c|c|}
\hline \multirow{3}{*}{ Umur } & \multicolumn{8}{|c|}{ Kualitas Hidup } & \multirow{3}{*}{ Sig. } & \multirow{3}{*}{ Correlation } \\
\hline & \multicolumn{2}{|c|}{ Baik } & \multicolumn{2}{|c|}{ Cukup } & \multicolumn{2}{|c|}{ Buruk } & \multicolumn{2}{|c|}{ Jumlah } & & \\
\hline & $\mathbf{n}$ & $\%$ & $\mathbf{n}$ & $\%$ & $\mathbf{n}$ & $\%$ & $\mathbf{N}$ & $\%$ & & \\
\hline $34-46$ tahun & 1 & 3,7 & 6 & 22,2 & 1 & 3,7 & 8 & 29,6 & 0,580 & $-0,112$ \\
\hline 47-59 tahun & 4 & 14,8 & 7 & 25,9 & 2 & 7,4 & 13 & 48,1 & & \\
\hline $60-72$ tahun & 2 & 7,4 & 3 & 11,1 & 1 & 3,7 & 6 & 22,2 & & \\
\hline Total & 7 & 25,9 & 16 & 59,3 & 4 & 14,8 & 27 & 100 & & \\
\hline
\end{tabular}

Sumber : Data Primer 
Berdasarkan hasil penelitian diketahui bahwa dari 27 responden, usia responden mayoritas adalah usia 47-59 tahun sebanyak 13 responden (41,9\%) dan minoritas responden berusia 60-72 tahun sebanyak 6 responden (19,45\%). Hasil uji spearman diperoleh nilai sig. $0,580>0,05$, dengan demikian tidak terdapat hubungan antara usia dengan kualitas hidup penderita kanker serviks.

TABEL 2

Tabulasi Silang Hubungan Pekerjaan dengan Kualitas Hidup Penderita Kanker Serviks

\begin{tabular}{|c|c|c|c|c|c|c|c|c|c|c|}
\hline \multirow{3}{*}{ Pekerjaan } & \multicolumn{8}{|c|}{ Kualitas Hidup } & \multirow{3}{*}{ Sig. } & \multirow{3}{*}{ Correlation } \\
\hline & \multicolumn{2}{|c|}{ Baik } & \multicolumn{2}{|c|}{ Cukup } & \multicolumn{2}{|c|}{ Buruk } & \multicolumn{2}{|c|}{ Jumlah } & & \\
\hline & $\mathbf{n}$ & $\%$ & $\mathbf{n}$ & $\%$ & $\mathbf{n}$ & $\%$ & $\mathbf{N}$ & $\%$ & & \\
\hline Bekerja & 2 & 7,4 & 1 & 3,7 & o & O & 3 & 11,1 & 0,105 & 0,319 \\
\hline Tidak Bekerja & 5 & 18,5 & 15 & 55,6 & 4 & 14,8 & 24 & 77,8 & & \\
\hline Total & 7 & 25,9 & 16 & 59,3 & 4 & 14,8 & 27 & 100 & & \\
\hline
\end{tabular}

Berdasarkan hasil penelitian diketahui bahwa dari diperoleh nilai sig. 0,105 > 0,05, dengan demikian 27 responden yang tidak bekerja sebanyak 24 tidak terdapat hubungan antara pekerjaan dengan responden $(88,9 \%)$ dan responden yang bekerja kualitas hidup penderita kanker serviks. sebanyak 3 orang $(11,1 \%)$. Hasil uji spearman

TABEL 3

Tabulasi Silang Hubungan Pendidikan dengan Kualitas Hidup Penderita Kanker Serviks

\begin{tabular}{|c|c|c|c|c|c|c|c|c|c|c|}
\hline \multirow{3}{*}{ Pendidikan } & \multicolumn{8}{|c|}{ Kualitas Hidup } & \multirow{3}{*}{ Sig. } & \multirow{3}{*}{ Correlation } \\
\hline & \multicolumn{2}{|c|}{ Baik } & \multicolumn{2}{|c|}{ Cukup } & \multicolumn{2}{|c|}{ Buruk } & \multicolumn{2}{|c|}{ Jumlah } & & \\
\hline & $\mathbf{n}$ & $\%$ & $\mathbf{n}$ & $\%$ & $\mathbf{n}$ & $\%$ & $\mathbf{N}$ & $\%$ & & \\
\hline Rendah & 4 & 14,8 & 7 & 25,9 & 2 & 7,4 & 13 & 48,1 & 0,727 & 0,070 \\
\hline Tinggi & 3 & 11,1 & 9 & 33,3 & 2 & 7,4 & 14 & 51,9 & & \\
\hline Total & 7 & 25,9 & 16 & 59,3 & 4 & 14,8 & 27 & 100 & & \\
\hline
\end{tabular}

Berdasarkan hasil penelitian diketahui bahwa (51,9\%). Hasil uji spearman diperoleh nilai sig. dari 27 responden yang memiliki pendidikan rendah $\quad 0,727>0,05$, dengan demikian terdapat tidak sebanyak 13 responden $(48,1 \%)$ dan responden terdapat hubungan antara pendidikan dengan pendidikannya tinggi adalah sebanyak 14 responden kualitas hidup penderita kanker serviks

TABEL 4

Tabulasi Silang Hubungan Status Pernikahan dengan Kualitas Hidup Penderita Kanker Serviks

\begin{tabular}{|c|c|c|c|c|c|c|c|c|c|c|}
\hline \multirow{3}{*}{ Umur } & \multicolumn{8}{|c|}{ Kualitas Hidup } & \multirow{3}{*}{ Sig. } & \multirow{3}{*}{ Correlation } \\
\hline & \multicolumn{2}{|c|}{ Baik } & \multicolumn{2}{|c|}{ Cukup } & \multicolumn{2}{|c|}{ Buruk } & \multicolumn{2}{|c|}{ Jumlah } & & \\
\hline & $\mathbf{n}$ & $\%$ & $\mathbf{n}$ & $\%$ & $\mathbf{n}$ & $\%$ & $\mathbf{N}$ & $\%$ & & \\
\hline Belum menikah & 0 & O & 1 & 3,4 & 0 & 0 & 1 & 3,4 & 0,834 & 0,042 \\
\hline Menikah & 6 & 22,2 & 13 & 48,1 & 3 & 11,1 & 22 & 81,5 & & \\
\hline Janda & 1 & 3,7 & 3 & 11,1 & 0 & 0 & 4 & 14,8 & & \\
\hline Total & 7 & 25,9 & 16 & $\begin{array}{c}\mathbf{5 9} \\
\mathbf{3}\end{array}$ & 4 & $\begin{array}{c}14, \\
8\end{array}$ & 27 & 100 & & \\
\hline
\end{tabular}

Berdasarkan hasil penelitian diketahui bahwa dari spearman diperoleh nilai sig. 0,834 > 0,05, dengan 27 responden yang Status pernikahan responden demikian tidak terdapat hubungan antara status mayoritas adalah menikah sebanyak 22 responden pernikahan dengan kualitas hidup penderita kanker $(81,5 \%)$ dan minoritas responden sebanyak belum serviks menikah sebanyak 1 responden (3,7\%). Hasil uji

TABEL 5

Tabulasi Silang Hubungan Penghasilan Keluarga dengan Kualitas Hidup Penderita Kanker Serviks

\begin{tabular}{|c|c|c|c|c|c|c|c|c|c|c|}
\hline \multirow{3}{*}{$\begin{array}{l}\text { Penghasilan } \\
\text { Keluarga }\end{array}$} & \multicolumn{8}{|c|}{ Kualitas Hidup } & \multirow{3}{*}{ Sig. } & \multirow{3}{*}{ Correlation } \\
\hline & \multicolumn{2}{|c|}{ Baik } & \multicolumn{2}{|c|}{ Cukup } & \multicolumn{2}{|c|}{ Buruk } & \multicolumn{2}{|c|}{ Jumlah } & & \\
\hline & $\mathbf{n}$ & $\%$ & $\mathbf{n}$ & $\%$ & $\mathbf{n}$ & $\%$ & $\mathbf{N}$ & $\%$ & & \\
\hline$\leq$ Rp. 2.037.000 & 5 & 18,5 & 13 & 4,8 & 0 & o & 18 & 66,7 & 0,073 & 0,350 \\
\hline > Rp. 2.037.000 & 2 & 7,4 & 3 & 11,1 & 4 & 14,8 & 9 & 33,3 & & \\
\hline Total & 7 & $\begin{array}{c}25 \\
9\end{array}$ & 16 & 59,3 & 4 & 14,8 & 27 & 100 & & \\
\hline
\end{tabular}


Berdasarkan hasil penelitian diketahui bahwa dari 27 responden yang Penghasilan keluarga $\leq \mathrm{Rp}$. 2.037.00o adalah sebanyak 18 responden $(66,7 \%)$ dan yang berpenghasilan keluarga Rp. >2.037.000 sebanyak belum menikah sebanyak 9 responden
(33,3\%). hasil uji spearman diperoleh nilai sig. 0,073 > 0,05, dengan demikian tidak terdapat hubungan antara penghasilan keluarga dengan kualitas hidup penderita kanker serviks.

TABEL 6

Tabulasi Silang Hubungan Pengetahuan dengan Kualitas Hidup Penderita Kanker Serviks

\begin{tabular}{|c|c|c|c|c|c|c|c|c|c|c|}
\hline \multirow{3}{*}{ Pengetahuan } & \multicolumn{8}{|c|}{ Kualitas Hidup } & \multirow{3}{*}{ Sig. } & \multirow{3}{*}{$\begin{array}{l}\text { Corre } \\
\text { lation }\end{array}$} \\
\hline & \multicolumn{2}{|c|}{ Baik } & \multicolumn{2}{|c|}{ Cukup } & \multicolumn{2}{|c|}{ Buruk } & \multicolumn{2}{|c|}{ Jumlah } & & \\
\hline & $\mathbf{n}$ & $\%$ & $\mathbf{n}$ & $\%$ & $\mathbf{n}$ & $\%$ & $\mathbf{N}$ & $\%$ & & \\
\hline Baik & 3 & 11,1 & 2 & 7,4 & $\mathrm{O}$ & $\mathrm{O}$ & 5 & 18,5 & 0,002 & 0,573 \\
\hline Cukup & 4 & 14,8 & 12 & 44,4 & 1 & 3,7 & 17 & 63,0 & & \\
\hline Kurang & $\mathrm{o}$ & o & 2 & 7,4 & 3 & 11,1 & 5 & 18,5 & & \\
\hline Total & 7 & 25,9 & 16 & 59,3 & 4 & 14,8 & 27 & 100 & & \\
\hline
\end{tabular}

Sumber : Data Primer

Berdasarkan hasil penelitian diketahui bahwa dari 27 responden yang variabel pengetahuan diketahui bahwa dari 27 responden, berpengetahuan baik 5 responden (18,5\%), berpengetahuan cukup 17 responden (63\%) dan berpengetahuan kurang sebanyak 5 responden (18,5\%). Hasil uji spearman diperoleh nilai sig. 0,002 < 0,05, dengan demikian terdapat hubungan antara pengetahuan dengan kualitas hidup penderita.

TABEL 7

Tabulasi Silang Hubungan Dukungan Keluarga dengan Kualitas Hidup Penderita Kanker Serviks

\begin{tabular}{|c|c|c|c|c|c|c|c|c|c|c|}
\hline \multirow{3}{*}{$\begin{array}{c}\text { Dukungan } \\
\text { Keluarga }\end{array}$} & \multicolumn{8}{|c|}{ Kualitas Hidup } & \multirow{3}{*}{ Sig. } & \multirow{3}{*}{ Correlation } \\
\hline & \multicolumn{2}{|c|}{ Baik } & \multicolumn{2}{|c|}{ Cukup } & \multicolumn{2}{|c|}{ Buruk } & \multicolumn{2}{|c|}{ Jumlah } & & \\
\hline & $\mathbf{n}$ & $\%$ & $\mathbf{n}$ & $\%$ & $\mathbf{n}$ & $\%$ & $\mathbf{N}$ & $\%$ & & \\
\hline Tidak & 0 & O & 2 & 7,4 & 3 & 11,1 & 5 & 18,5 & 0,005 & $-0,522$ \\
\hline Mendukung & & & & & & & & & & \\
\hline Mendukung & 7 & 25,9 & 14 & 51,9 & 1 & 3,4 & 22 & 81,5 & & \\
\hline Total & 7 & 25,9 & 16 & 59,3 & 4 & 14,8 & 27 & 100 & & \\
\hline
\end{tabular}

Berdasarkan hasil penelitian diketahui bahwa dari 27 responden yang variabel Dukungan keluarga dalam kategori tidak mendukung adalah sebanyak 5 responden $(18,5 \%)$ dan yang mendukung sebanyak sebanyak 22 responden (81,5\%). Hubungan antara dukungan keluarga dengan kualitas hidup penderita

\section{Hasil Kualitatif}

\section{Informan I}

Ny.SA menderita kanker serviks stadium II, pertama kali divonis oleh dokter menderita kanker serviks pada bulan Mei , berumur 45 tahun, pekerjaannya sebagai petani kopi, pendidikannya tinggi yaitu SMA, status pernikahannya yaitu menikah, dan penghasilan keluarganya perbulan > Rp. 2.037.000 tetapi ia mengatakan penghasilan keluarganya kurang untuk membiaya biaya perobatannya walaupun sudah dibantu biaya BPJS.

\section{Pengetahuan Ny. SA tentang kanker serviks}

"Setahu ku kanker serviks dari keturunan. Mamak ku pernah kena tumor di rahimnya, kakak ku juga meninggal gara-gara kanker rahim, meninggal waktu usianya 60 tahun. Ku kira dulu kanker hampir sama kayak tumor rahim." kanker serviks menunjukkan hasil uji spearman diperoleh nilai sig. 0,005 $<0,05$, dengan demikian terdapat hubungan antara dukungan keluarga dengan kualitas hidup penderita kanker serviks.

\section{Dukungan keluarga Ny. SA tentang kanker serviks}

"Aku berobat sama mamak dan suami ku, anakanak tinggal di kampung karena harus sekolah tapi kalau malam sering nelpon nanya kabar sambil bilang mamak cepat sembuh ya mak."

\section{Dimensi kesehatan fisik Ny. SA}

"Awalnya aku keputihan banyak warnanya putih cair dan gak berhenti-berhenti satu hari bisa ganti celana dalam 4-5 kali, gak ada sakit-sakit perut gitu."

\section{Kondisi dimensi kesehatan psikologis Ny. SA}

"Aku sedih kali kenapa Tuhan ngasih penyakit aku kayak gini, kenapa harus aku yang kena, tega kali Tuhan samaku, ntah apa dosaku. Sampai sekarang aku masih sering nangis dan murung, kasian anakanak ku lah masih kecil-kecil masih butuh aku, aku jadi beban mereka aja.“ 


\section{Dimensi hubungan sosial Ny. SA}

"Aku malu sama kawan-kawanku di kampung karena aku botak, waktu lagi beladang pernah dibuka orang itu songkok ku nampak kepala ku yang botak terus aku pulang ke rumah nangis."

\section{Dimensi lingkungan Ny. SA}

"Gak nyaman udah aku di lingkungan tempat tinggal ku itu karena orang-orang di lingkunganku itu suka nyerita-nyeritain penyakitku ini, kalau ngisi waktu luang di rumah aja gak kemana-kemana."

\section{Religiusitas Ny. SA}

"Aku gak pernah lagi lah ke gereja lagilah selama kena penyakit."

\section{Kualitas Hidup Ny. SA}

"Menurutku sekarang kualitas hidup ku sekarang buruk. Gak ada lagi semangat hidup ku, tiap hari nangis, malu aku sama penyakitku ini."

\section{PEMBAHASAN}

\section{Hubungan Usia dengan Kualitas Hidup Penderita Kanker Serviks}

Hasil penelitian ini menunjukkan dari hasil uji spearman tidak terdapat hubungan antara usia dengan kualitas hidup penderita kanker serviks. Hasil penelitian ini tidak sejalan dengan penelitian yang dilakukan oleh Wagner, Abbot, dan Lett yang menemukan adanya hubungan usia dalam aspek-aspek kehidupan individu dalam meningkatkan kualitas hidup.(Suryapratama and Pramono 2012)

Dari hasil kualitatif didapatkan, informan I yang berusia 45 tahun mempunyai kualitas hidup buruk, informan II mempunyai usia umur 45 tahun kualitas hidupnya baik dan informan III mempunyai kualitas hidup cukup berusia 47 tahun. Usia tidak berhubungan dengan kualitas hidup dikarenakan pada individu terjadi proses kematangan dari hasil belajar dari lingkungan, sosial dan kematangan fungsi secara fisik dan psikologis.(Hasanah, Zaliha, and Mahiran 2011)

Menurut peneliti hal ini berkaitan dengan pola pikir dan kematangan seseorang untuk menilai jenis stressor yang datang, kemampuan beradaptasi digunakan untuk memengaruhi perilaku sesorang dalam mengambil keputusan, serta usia bukanlah penentu kematangan psikologis seseorang. Penelitian ini saling menguatkan anatara secara kualitatif dan kuantitatif.

\section{Hubungan Pekerjaan dengan Kualitas Hidup Penderita Kanker Serviks}

Hasil penelitian ini menunjukkan dari hasil uji spearman tidak terdapat hubungan antara pekerjaan dengan kualitas hidup penderita kanker serviks. Penelitian ini tidak sejalan dengan penelitian ButarButar(NFM 2009)hasil analisis yang dilakukan dengan uji chi square didapat nilai $\mathrm{p}=0,004$ yang artinya bahwa ada hubungan yang signifikan antara pekerjaan dengan kualitas hidup pasien.
Dari hasil kualitatif didapatkan, informan I mengatakan bekerja sebagai petani kopi di ladangnya milik sendiri bersama suami, informan I mempunyai kualitas hidup buruk, informan II adalah tidak bekerja namun ia mempunyai kualitas hidup baik dan informan III juga tidak bekerja dan mempunyai kualitas hidup cukup.

Menurut peneliti pekerjaan seseorang akan berhubungan dengan penghasilan keluarga yaitu berupa uang maupun gaji, penghasilan keluarga yang rendah tidak lagi menghalangi seseorang dalam memanfaatkan fasilitas kesehatan sebagai usahanya untuk sembuh dari penyakit yang dideritanya yaitu kanker serviks dikarenakan semua responden yang berobat di RSUD Pirngadi mendapatkan bantuan kesehatan pemerintah yaitu BPJS. Penelitian ini saling menguatkan antara kualitatif dan kuantitatif.

\section{Hubungan Pendidikan dengan Kualitas Hidup Penderita Kanker Serviks}

Hasil penelitian ini menunjukkan dari hasil uji spearman tidak terdapat hubungan antara pendidikan dengan kualitas hidup penderita kanker serviks. Penelitian ini tidak sejalan dengan penelitian Sumarni menyebutkan ada hubungan pendidikan dengan kualitas hidup penderita kanker serviks dengan menggunakan uji chi-square didapatkan $(\mathrm{p}=0,000)$.(Nazir 2006)Penelitian ini juga tidak sejalan dengan Welly, ia menyatakan bahwa dari hasil penelitian yang dilakukannya adanya hubungan bermakna pekerjaan dengan kualitas hidup.(Hasibuan 2015)

Dari hasil kualitatif didapatkan, informan I memiliki pendidikan yang tinggi yaitu (SMA) dan ia mempunyai kualitas hidup buruk. Informan II adalah juga berpendidikan tinggi (SMA) dan kualitas hidup informan II baik dan informan III juga berpendidikan tinggi (SMA) mempunyai kualitas hidup cukup.

Menurut peneliti hal ini dikarenakan penderita kanker serviks yang memiliki pendidikan tinggi belum memanfaatkan kognitifnya yang baik untuk menerima, mencari, informasi tentang perawatan dirinya. Penelitian ini saling menguatkan antara kualitatif dan kuantitatif.

\section{Hubungan Status Pernikahan dengan Kualitas Hidup Penderita Kanker Serviks}

Hasil penelitian ini menunjukkan dari hasil uji spearman tidak terdapat hubungan antara status pernikahan dengan kualitas hidup penderita kanker serviks. Hasil penelitian ini sejalan dengan Novianti yang menyebutkan tidak terdapat hubungan status perkawinan dengan kualitas hidup.(Sumarni, Amiruddin, and Leida 2015)

Informan I status pernikahannya yaitu menikah, memiliki kualitas hidup buruk, Informan II status pernikahannya yaitu menikah, memiliki kualitas hidup 
baik dan Informan III status pernikahannya yaitu menikah, memiliki kualitas hidup cukup.

Menurut peneliti, janda ataupun yang yang belum menikah asal tidak dalam keadaan depresi, dukungan dari siapapun dapat diterimanya dengan baik. Tidak hanya mengharapkan dukungan dari suami seperti orang yang berstatus menikah tetapi dukungan dari saudara-saudara mereka ataupun teman dapat memengaruhi motivasi penderita, begitu juga sebalikya yang status pernikahannya menikah pun apabila dalam keadaan depresi dan terpuruk, mendapat dukungan dari suami pun tidak akan memengaruhi motivasi dan sikapnya. Jadi status perkawinan tidak berhubungan dengan kualitas hidup. Penelitian ini saling menguatkan antara kualitatif dan kuantitatif.

\section{Hubungan Penghasilan Keluarga dengan Kualitas Hidup Penderita Kanker Serviks}

Hasil penelitian ini menunjukkan dari hasil uji spearman tidak terdapat hubungan antara penghasilan keluarga dengan kualitas hidup penderita kanker serviks. Hasil ini tidak sejalan dengan Rukmaliza yang menyebutkan bahwasannya penghasilan berhubungan dengan kualitas hidup. (Rukmaliza and Kep 2014)

Hasil kualitatif Informan I berpenghasilan keluarga > Rp. 2.037.000 tetapi ia mengatakan penghasilan keluarganya kurang untuk membiaya biaya perobatannya walaupun sudah dibantu biaya BPJS dan mempunyai kualitas hidup buruk, informan II berpenghasilan keluarga $\leq$ Rp. 2.037.000 ia mengatakan dengan penghasilannya itu bukanlah masalah ia tetap dapat menjalani perobatan karena dibantu oleh BPJS dan memiliki kualitas hidup baik, informan III berpenghasilan keluarga $\leq$ Rp. 2.037.00o ia mengatakan dengan penghasilannya yang segitu ia tetap mendapatkan fasilitas kesehatan karena dibantu oleh BPJS dan memiliki kualitas hidup cukup.

Hasil uraian di atas menurut peneliti bagi penderita yang telah menerima penyakitnya walaupun penghasilan keluarga mereka di bawah UMK, untuk kebutuhan perobatan tidak menjadi masalah lagi bagi dirinya karena mereka telah terbantu dengan adanya BPJS tetapi bagi penderita yang dalam keadaan depresi dan belum menerima penyakitnya, walaupun penghasilan keluarga di atas UMK dan dibantu juga oleh BPJS hal ini tetap menjadi beban dan tetap merasa kekurangan, jadi penghasilan keluarga tidak berhubungan dengan kualitas hidup. Penelitian ini saling menguatkan antara kualitatif dan kuantitatif.

\section{Hubungan Pengetahuan dengan Kualitas Hidup Penderita Kanker Serviks}

Hasil penelitian ini menunjukkan dari hasil uji spearman terdapat hubungan antara pengetahuan dengan kualitas hidup penderita kanker serviks. Secara kualitatif, dari 3 informan memiliki pengetahuan yang berbeda tentang kanker serviks. Hasil kualitatif informan I yaitu hanya mengetahui bahwa faktor risiko kanker serviks merupakan keturunan. Kualitas hidup informan yaitu buruk, ia tidak lagi mempunyai semangat hidup, tiap hari menangis dan malu sama penyakit yang dideritanya.

Informan II mengetahui faktor risiko kanker serviks dari kebersihan genetalia, banyak patner sex, pemakaian alat kontrasepsi, keturunanan dan mengetahui gejala kanker serviks yaitu sakit pada perut sakit, pinggang sakit dan perdarahan saat berhubungan seksual dan keputihan, serta mengetahui vaksin dapat mencegah kanker serviks, mengetahui pengobatan kanker serviks dapat dengan kemo dan sinar dan mengetahui efek dari kemo adalah kebotakan pada rambut. Kualitas hidup informan II yaitu baik dirinya sekarang sudah menerima penyakitnya tapi semangat untuk sembuhnya tinggi, dia tidak memikirkankan perkataan-perkatan orang yang tidak enak kepada dirinya serta kehidupan sosialnya pun baik.

Informan III mengetahui faktor risiko dari kanker serviks yaitu nikah usia muda dan hubungan sex dengan banyak patner, paritas, dan keturunan serta mengetahui pengobatan kanker serviks yaitu dengan kemoterapi. Kualitas hidup informan cukup, ia mengatakan kalau dulu dirinya menangis terus karena penyakit yang dideritanya, tidak terima dan malu jika ia melihat dirinya sendiri karena tubuhnya yang kurus sekali dan pucat, sekarang sudah lebih iklas menerima diri walaupun terkadang masih ada rendah diri.

Menurut peneliti semakin banyak yang ia tahu tentang penyakitnya maka kualitas hidupnya semakin baik karena ia mengetahui apa yang harus dilakukannya untuk pengendalian, pengobatan dan penanganan penyakitnya sehingga berhubungan dengan kualitas hidupnya. Pengetahuan memiliki hubungan yang signifikan dengan kualitas hidup, secara kuantitatif dan kualitatif hasil penelitian ini saling menguatkan.

\section{Hubungan Dukungan Keluarga dengan Kualitas Hidup Penderita Kanker Serviks}

Hasil penelitian ini menunjukkan dari hasil uji spearman terdapat hubungan antara dukungan dengan kualitas hidup penderita kanker serviks. Penelitian oleh Jin, Dong, Dong dan Min berpendapat bahwa dukungan sosial berpengaruh positif terhadap kesehatan psikologis, kesejahteraan fisik, dan kualitas hidup seseorang.(Wardhani, Moetmainnah, and Yazid 2012)

Wawancara dengan 3 informan menghasilkan, bahwa informan I memiliki kualitas hidup informan buruk. Informan II berkualitas hidup baik. Informan III kualitas hidup informan pasien kanker serviks stadium IV yaitu cukup. Menurut peneliti dukungan keluarga bagi penderita kanker serviks dapat membantu penderita mempunyai perasaan yang nyaman yang dapat meningkatkan kualitas hidup mereka tetapi pada 
akhirnya kembali ke penderita itu sendiri. Secara penelitian kuantitatif dan kualitatif hasil penelitian ini saling menguatkan.

\section{E. SIMPULAN DAN SARAN}

Terdapat hubungan antara karakteristik individu (pengetahuan) dan dukungan keluarga dengan kualitas hidup penderita kanker serviks di RSUD Dr. Pirngadi Kota Medan Tahun . Tidak terdapat hubungan antara karakteristik individu (usia, pekerjaan, status pernikahan, pendidikan, penghasilan) dengan kualitas hidup penderita kanker serviks di RSUD Dr. Pirngadi Kota Medan Tahun . Hasil kualitatif dan kuantitatif saling menguatkan dan pada hasil kualitatif ditemukan faktor baru yaitu religiutas.

Kepada petugas kesehatan yang bertugas di RSUD. Dr. Pirngadi Kota Medan agar berupaya meningkatkan pengetahuan menambah pemahaman tentang kanker serviks sehingga kualitas hidup penderita mengarah ke arah yang lebih baik.

\section{UCAPAN TERIMA KASIH}

Tim penulis mengucapkan terima kasih kepada RSUD. PIRNGADI MEDAN karena telah mengijinkan melakukan penelitian di Instansi tersebut.

\section{DAFTAR RUJUKAN}

[1] Creswell, John W. 2010. "Research Design Pendekatan Kualitatif, Kuantitatif, Dan Mixed." Yogyakarta: Pustaka Pelajar.

[2] Darmawati, Darmawati. 2010. "Kanker Serviks Wanita Usia Subur." Idea Nursing Journal 1(1): 9-13.

[3] Fitriana, Nimas Ayu, And Tri Kurniati Ambarini. 2012. "Kualitas Hidup Pada Penderita Kanker Serviks Yang Menjalani Pengobatan Radioterapi." Jurnal Psikologi Klinis Dan Kesehatan Mental 1(2): 123-29.

[4] Gustiana, Dwikha, Yulia Irvani Dewi, And Sofiana Nurchayati. 2014. "Faktor-Faktor Yang Berhubungan Dengan Perilaku Pencegahan Kanker Serviks Pada Wanita Usia Subur." Jurnal Online Mahasiswa Program Studi Ilmu Keperawatan Universitas Riau 1(2): 1-8.

[5] Hasanah, C I, A R Zaliha, And M Mahiran. 2011. "Factors Influencing The Quality Of Life In Patients With Hiv In Malaysia." Quality Of Life Research 20(1): 91-100.

[6] Hasibuan, Khairun Nikmah. 2015. "Karakteristik Penderita Kanker Serviks Yang Dirawat Inap Di Rsud Arifin Achmad Pekanbaru Tahun 2011-2013." Gizi, Kesehatan Reproduksi Dan Epidemiologi 1(3).

[7] Hasnani, Fenti. 2012. "Spiritualitas Dan Kualitas Hidup Penderita Kanker Serviks.” Jurnal Health Quality 3(2): 69-140.

[8] Imam Rasjidi, Sp O G. 2013. 100 Questions \& Answers Kanker Pada Wanita. Elex Media Komputindo.
[9] Indonesia, Kementerian Kesehatan Republik. 2013. "Riset Kesehatan Dasar 2013." Jakarta: Badan Penelitian Dan Pengembangan Kesehatan Ri.

[10] Kasdu, Dini. 2005. Solusi Problem Wanita Dewasa. Niaga Swadaya.

[11] Lestari, Indah Siti, S K M Yuli Kusumawati, And Kusuma Estu Werdani. 2016. "Faktor-Faktor Yang Mempengaruhi Kesediaan Wus Dalam Melakukan Deteksi Dini Kanker Serviks Di Puskesmas Manahan Surakarta."

[12] Nazir, Kiki Abdurachim. 2006. "Penilaian Kualitas Hidup Pasien Pasca Bedah Pintas Koroner Yang Menjalani Rehabilitasi Fase Iii Dengan Menggunakan Sf-36."

[13] Nfm, Nofitri. 2009. "Gambaran Kualitas Hidup Penduduk Dewasa Pada Lima Wilayah Di Jakarta." Depok: Fakultas Psikologi Universitas Indonesia.

[14] Rohmah, Anis Ika Nur, And Khoridatul Bariyah. 2015. “Kualitas Hidup Lanjut Usia.” Jurnal Keperawatan 3(2).

[15] Rukmaliza, Ns Trisna, And S Kep. 2014. "Hubungan Karakteristik Individu Dengan Kualitas Hiduprnpasien Gagal Ginjal Kronik Yang Menjalani Hemodialisis Dirninstalasi Dialisis Blud Rumah Sakit Umum Dr. Zainoel Abidinrnbanda Aceh Tahun 2013." Etd Unsyiah.

[16] Sulistiowati, Eva, And Anna Maria Sirait. 2015. "Pengetahuan Tentang Faktor Risiko, Perilaku Dan Deteksi Dini Kanker Serviks Dengan Inspeksi Visual Asam Asetat (Iva) Pada Wanita Di Kecamatan Bogor Tengah, Kota Bogor." Buletin Penelitian Kesehatan 42(3 Sep): 193-202.

[17] Sumarni, Sri, Ridwan Amiruddin, And Ida M Thaha Leida. 2015. "Faktor Yang Berhubungan Dengan Kualitas Hidup Penderita Hipertensi Di Wilayah Kerja Puskesmas Segeri.” Jurnal Unhas, Bagian Epidemiologi Fakultas Kesehatan Masyarakat Universitas Hasanuddin, Sulawesi.

[18] Suryapratama, Satya Ariza, And Besari Adi Pramono. 2012. "Karakteristik Penderita Kanker Serviks Di Rsup Dr. Kariadi Semarang Tahun 2010."

[19] Wardhani, Hanif Alienda, Siti Moetmainnah, And Noor Yazid. 2012. "Hubungan Kejadian Carcinoma Cervicis Uteri Dengan Umur, Status Perkawinan, Dan Paritas Di Rsup Dr Kariadi Semarang Periode Januari-Maret 2011.” Jurnal Kedokteran Muhammadiyah 1(3).

[20] Wigati, Putri Wahyu. 2016. "Analisis Jalur Dengan Health Belief Model Tentang Penggunaan Skrining Inspeksi Visual Asam Asetat Untuk Deteksi Dini Kanker Serviks Pada Wanita Usia Subur Di Kota Kediri.”

[21] Zega, S, And C T Siregar. 2013. "Kualitas Hidup Pasien Kanker Payudara Yang Menjalani Kemoterapi Di Rumah Sakit Umum Pusat Haji Adam Malik Medan.” Medan: Fakultas Keperawatan Universitas Sumatera Utara. 